Pesq. Vet. Bras. 30(1):79-86, janeiro 2010

\title{
Perfil eletroforético e concentração de imunoglobulinas G (IgG) do soro sanguíneo de cabras Saanen com mastite experimental induzida por Staphylococcus aureus suplementadas com vitamina $\mathrm{E}^{1}$
}

\author{
Joandes H. Fonteque ${ }^{2 *}$, Aguemi Kohayagawa ${ }^{3}$, Cláudio R.S. Mattoso ${ }^{3}$, Sônia \\ T.A. Lopes ${ }^{4}$, Paulo R.O. Paes ${ }^{5}$, Maria Luiza Cassetari ${ }^{6}$ e Hélio Langoni ${ }^{7}$
}

\begin{abstract}
Fonteque J.H., Kohayagawa A., Mattoso C.R.S., Lopes S.T.A., Paes P.R.O., Cassetari M.L. \& Langoni H. 2010. [Electrophoretic profile and concentration of immunoglobulins G (IgG) in blood serum of Saanen goats with experimental mastitis induced by Staphylococcus aureus suplemented with vitamin E.] Perfil eletroforético e concentração de imunoglobulinas G ( $\mathrm{IgG}$ ) do soro sanguíneo de cabras Saanen com mastite experimental induzida por Staphylococcus aureus suplementadas com vitamina E. Pesquisa Veterinária Brasileira 30(1):79-86. Departamento de Medicina Veterinária, Hospital de Clínica Veterinária, Centro de Ciências Agroveterinárias, Universidade do Estado de Santa Catarina, Lages, SC 88520-000, Brazil. E-mail: fonteque@cav.udesc.br

The objective was to evaluate the electrophoretic profile of proteins and serum concentration of immunoglobulin $\mathrm{G}(\mathrm{IgG})$ in Saanen goats with mastitis experimentally induced by Staphylococcus aureus (dl- $\alpha$-tocopherol acetated). 14 adult goats, (supplemented with vitamin E DL- $\alpha$-tocopherol) primiparous pregnant, seronegative for caprine arthritis encephalitis (CAEV), clinically healthy, were divided into two groups of seven animals: Not supplemented group (G1) and group supplemented with $2.000 \mathrm{UI}$ of DL- $\alpha$-tocopherol (G2 Vit E), by intramuscular injection on the day of the parturition and seven days later. At the 9th day after delivery 300 UFCs of the $S$. aureus ATCC 225923 strain were inoculated into the left half of the mammary gland of each animal. The mastitis was determined through collection of milk samples for evidence of infection by means of bacteriological examination, somatic cell count (SCC) and California Mastitis Test (CMT). Then samples were collected after 12, 24, 48 and 72 hours, antimicrobial intra-mammary gland treatment was initiated, with new evaluation 48 hours after treatment. The electrophoretic profile of serum protein of the goats, showed five fractions, as follows: albumin and globulin ( $\alpha, \beta 1, \beta 2$ e $\gamma$-globulin). There was an increase in the production of $\gamma$-globulin and lower production of $\beta 2$-globulin fraction 12 hours after infection, and faster decrease in the supplemented group, showing the influence of vitamin $E$ in the production of acute phase proteins. There was no influence of vitamin $E$ in the serum concentration of immunoglobulin $G(\lg G)$ in supplemented animals. The supplementation with vitamin $E$ increased the concentration of immunoglobulin and decreased the production of acute phase proteins, probably the antioxidant effect minimizing the tissue injury during the inflammatory process in the mammary gland.
\end{abstract}

INDEX TERMS: Goats, Saanen, mastitis, vitamin E, electrophoresis, immunoglobulin.

\footnotetext{
${ }^{1}$ Recebido em 2 de junho de 2009.

Aceito para publicação em 14 de setembro de 2009.

2 Departamento de Medicina Veterinária, Centro de Ciências Agroveterinárias, Universidade do Estado de Santa Catarina (UDESC), Av. Luiz de Camões 2090, Lages, SC 88520-000, Brasil. *Autor para correspondência: fonteque@cav.udesc.br

${ }^{3}$ Departamento de Clínica Médica, Faculdade de Medicina Veterinária e Zootecnia (FMVZ), Universidade Estadual Paulista Júlio de Mesquita Filho (Unesp), Rubião Júnior s/n, Cx. Postal 560, Botucatu, SP 18618-000, Brasil.
}

\footnotetext{
${ }^{4}$ Departamento de Clínica de Pequenos Animais, Universidade Federal de Santa Maria (UFSM), Av. Roraima 1000, Cidade Universitária, Bairro Camobi, Santa Maria, RS 97105-900, Brasil.

${ }^{5}$ Departamento de Clínica e Cirurgia Veterinária, Universidade Federal de Minas Gerais (UFMG), Av. Antônio Carlos 6627, Cx. Postal 567, Belo Horizonte, MG 30123-970, Brasil.

${ }^{6}$ Departamento de Nutrição, Instituto de Biociências (IB), Unesp, Botucatu, SP.

${ }^{7}$ Departamento de Higiene Sanitária e Saúde Pública, FMVZ, Unesp, Botucatu, SP.
} 
RESUMO.- O objetivo do trabalho foi avaliar o perfil eletroforético das proteínas e a concentração sérica de imunoglobulina G (IgG) em cabras da raça Saanen com mastite induzida experimentalmente por Staphylococcus aureus e suplementadas com vitamina $\mathrm{E}$ (acetato de dl- $\alpha$-tocoferol). Utilizaram-se 14 cabras adultas, gestantes, primíparas, com sorologia negativa para Artrite Encefalite Caprina (CAEV), clinicamente sadias, divididas em dois grupos experimentais de sete animais. Grupo não suplementado (G1) e grupo suplementado com 2.000 U.I. de acetato de dl- $\alpha$-tocoferol (G2 Vit E) via intramuscular no dia do parto e sete dias após o parto. Ao nono dia do pós-parto foram inoculados 300 UFCs da cepa de S. aureus ATCC 225923, na metade esquerda da glândula mamária de cada animal. A mastite foi determinada pela colheita das amostras de leite para a comprovação da infecção, por meio de exames bacteriológicos, contagem de células somáticas (CCS) e California Mastitis Test (CMT), a partir deste momento foram efetuadas colheitas às 12, 24, 48 e 72 horas, sendo posteriormente instituído o tratamento intramamário com antimicrobiano e nova avaliação 48 horas após o tratamento. O perfil eletroforético em gel de agarose das proteínas séricas das cabras, apresentaram cinco frações, sendo: albumina e globulinas $(\alpha, \beta 1, \beta 2$ e $\gamma)$. Houve aumento na produção de $\gamma$-globulina e menor produção da fração $\beta 2$-globulina 12 horas após a infecção, com os valores reduzindo mais rapidamente no grupo suplementado, evidenciando a influência da vitamina $E$ na diminuição da produção das proteínas de fase aguda. Não houve influência da vitamina $E$ na concentração sérica de imunoglobulina $G(\lg G)$ nos animais suplementados. A suplementação com vitamina $\mathrm{E}$ aumentou a concentração de imunoglobulinas e diminuiu a produção de proteínas de fase aguda, provavelmente pelo efeito antioxidante minimizando a lesão tecidual durante 0 processo inflamatório localizado na glândula mamária.

TERMOS DE INDEXAÇÃO: Cabras, Saanen, mastite, vitamina $\mathrm{E}$, eletroforese, imunoglobulina.

\section{INTRODUÇÃO}

A mastite constituiu-se um dos maiores problemas da exploração leiteira por alterar a qualidade do leite e de seus derivados (Silva 1991), diminuir a produção e aumentar os custos, sendo de grande interesse econômico na criação de cabras especializadas. A vitamina $E$ tem mostrado no período do periparto em vacas leiteiras, efeito protetor contra a ação de radicais livres produzidos na glândula mamária durante o processo inflamatório. Além da sua ação na melhora da função dos neutrófilos, controlando a produção de radicais livres durante o processo de "explosão respiratória" e consequentemente diminuindo a lesão tecidual adjacente, a vitamina E interfere também na produção de prostaglandinas, leucotrienos e tromboxane (Reddy \& Frey 1990, Weiss et al. 1994, Mcdowell et al. 1996). Weiss et al. (1990), Smith et al. (1984) e Smith et al. (1985) observaram que bovinos leiteiros suplementados com vitamina $\mathrm{E}$ apresentaram diminuição na severidade e na incidência de mastite clínica. Devido à escassez de trabalhos científicos enfatizando os efeitos da suplementação de vitamina E no período periparturiente em cabras com mastite, este trabalho teve como objetivo evidenciar as alterações no perfil eletroforético das proteínas séricas e na concentração de imunoglobulinas G (lgG) em cabras Saanen com mastite experimental induzida por Staphylococcus aureus suplementadas com vitamina $\mathrm{E}$.

\section{MATERIAL E MÉTODOS}

O trabalho foi realizado no Laboratório Clínico Veterinário "Aguemi Kohayagawa" do Departamento de Clínica Veterinária e no Laboratório de Microbiologia do Núcleo de Pesquisas em Mastite (Nupemas) do Departamento de Higiene Veterinária e Saúde Pública da Faculdade de Medicina Veterinária e Zootecnia (FMVZ), Unesp, Campus de Botucatu, SP. Foram utilizadas 14 cabras da raça Saanen, de 8-12 meses de idade, pesando entre 28 e $35 \mathrm{~kg}$, gestantes, primíparas, criadas em regime intensivo no Hospital Veterinário da Faculdade de Medicina Veterinária e Zootecnia, Unesp, Campus de Botucatu, SP. Os animais foram mantidos em baias, recebendo ração concentrada, feno de "coastcross" (Cynodon dactylon), sal mineral e água à vontade. As cabras foram consideradas clinicamente sadias a partir de exames clínicos e laboratoriais e apresentaram sorologia negativa para Artrite Encefalite Caprina (CAEV) por meio do Teste de Imunodifusão Radial ${ }^{8}$. Os grupos experimentais constituíram-se de sete animais, sendo: grupo não suplementado com vitamina $E(G 1)$ e grupo suplementado com 2.000 U.I. de vitamina E (G2 Vit. E) (acetato de dl- $\alpha$-tocoferol) ${ }^{9}$, via intramuscular, no dia do parto e sete dias após o parto. Ao oitavo dia pós-parto foram realizadas colheitas de sangue para a determinação das proteínas séricas totais e para a realização do fracionamento eletroforético das proteínas séricas, concentração sérica de vitamina E, e amostras de leite para realização da contagem de células somáticas (CCS), Califormia Mastits Test (CMT) e exames bacteriológicos que serviram como controle (M1). Ao nono dia pós-parto foram inoculadas na metade esquerda da glândula mamária via orifício do teto, 300 unidades formadoras de colônia (UFCs) de Staphylococcus aureus, cepa ATCC 25923, em cada animal. A partir deste momento, os animais foram acompanhados diariamente por meio de exames clínicos e laboratoriais. Quando a secreção da glândula mamária determinou alterações nos exames bacteriológicos, contagem de células somáticas (CCS) e California Mastitis Test (CMT) foram iniciadas as colheitas de sangue para a obtenção do soro, sendo denominado de momento dois (M2). A partir de M2 novas colheitas foram efetuadas às 12 (M3), 24 (M4), 48 (M5) e 72 horas (M6) e instituído o tratamento intramamário com antimicrobiano e nova avaliação 48 horas após o tratamento (M7). O California Mastits Test (CMT) foi realizado conforme descrito por Schalm \& Noordlander (1957). A contagem de células somáticas (CCS) foi realizada de acordo com a técnica descrita por Preescot \& Bredd (1910) e a coloração pelo método de Broadhurst \& Paley (1939) modificado (Santos \& Virela 1983). Os esfregaços foram realizados e examinados em duplicata de acordo com Lima Júnior (1991). O exame bacteriológico

\footnotetext{
${ }^{8}$ Caprine Arthritis-Encephalitis Antibody Test $\mathrm{Kit}^{\circledR}$, Veterinary Diagnostic Technology, 4890 van Gordon St Wheat Ridge CO 80033, Colorado, USA).

${ }^{9}$ Monovin $\mathrm{E}^{\circledR}$, Laboratório Bravet LTDA, Visconde de Santa Cruz 276, Engenho Novo, Rio de Janeiro, RJ.
} 
constituiu-se de identificação quanto à morfologia e disposição das células, características tintoriais ao Gram e a prova da catalase. $\mathrm{O}$ cultivo e a identificação dos microrganismos foram seguidos de acordo com as técnicas utilizadas no Laboratório de Microbiologia do Nupemas, Unesp, Campus de Botucatu, SP, preconizados por Carter \& Cole Júnior (1990). Foram colhidos $10 \mathrm{~mL}$ de sangue total, mediante venipunção jugular, utilizandose tubos sem anticoagulante a vácuo ${ }^{10}$ para a obtenção do soro e as amostras estocadas a $-20^{\circ} \mathrm{C}$, até o momento da determinação das concentrações das proteínas séricas, imunoglobulinas $\mathrm{G}(\mathrm{IgG})$ e vitamina $\mathrm{E}$. A proteína total sérica foi determinada pelo método de Biureto, utilizando-se kits comerciais ${ }^{11}$. A separação das frações protéicas séricas foi determinada pela técnica de eletroforese em gel de agarose ${ }^{12}$ em tampão Veronal/EDTA $0,05 \mathrm{M}$ e pH 8,6, corado em Negro de amido a 0,2\% em ácido acético a $5 \%$ e a leitura efetuada por densitometria em 520 nanômetros ${ }^{13}$. A concentração de imunoglobulina $G$ (IgG) foi determinada por meio da imunodifusão radial ${ }^{14}$. A determinação da vitamina $\mathrm{E}$ sérica foi realizada por meio da Cromatografia Líquida de Alta Performance (HPLC) ${ }^{15}$, seguindo as recomendações de Arnaud (1991). As análises estatísticas foram realiza-

Quadro 1 . Medianas e análise estatística de sete repetições dos resultados da reação do Califórnia Mastitis Test* no leite da glândula mamária esquerda de cabras Saanen não suplementadas (G1) e suplementadas com 2.000Ul de vitamina E no dia do parto e 7 dias após o parto (G2 Vit. E), nos momentos controle (M1), mastite (M2), 12 horas após a mastite (M3), 24 horas após a mastite (M4), 48 horas após a mastite (M5), 72 horas após a mastite (M6) e 48 horas após o tratamento com antibiótico intramamário (M7)

\begin{tabular}{cccccccc}
\hline \multirow{2}{*}{ Grupos } & \multicolumn{7}{c}{ Momentos } \\
\cline { 2 - 7 } & $\mathrm{M} 1$ & $\mathrm{M} 2$ & $\mathrm{M} 3$ & $\mathrm{M} 4$ & $\mathrm{M} 5$ & $\mathrm{M} 6$ & $\mathrm{M} 7$ \\
\hline \multirow{3}{*}{ G1 } & Controle & Mastite & $12 \mathrm{~h} \mathrm{PM}$ & $24 \mathrm{PM}$ & $48 \mathrm{PM}$ & $72 \mathrm{PM}$ & $48 \mathrm{PT}$ \\
G2 (Vit E) & $0,0^{\mathrm{Aa}}$ & $2,0^{\mathrm{Ba}}$ & $3,0^{\mathrm{Bb}}$ & $2,0^{\mathrm{Bc}}$ & $2,0^{\mathrm{Bb}}$ & $1,0^{\mathrm{Bb}}$ & $1,0^{\mathrm{Bb}}$ \\
& $0,0^{\mathrm{Aa}}$ & $0,5^{\mathrm{Aa}}$ & $0,5^{\mathrm{Ac}}$ & $1,0^{\mathrm{Ac}}$ & $0,5^{\mathrm{Ac}}$ & $1,0^{\mathrm{Ab}}$ & $0,5^{\mathrm{Aa}}$
\end{tabular}

*Atribui-se a reação (-) no CMT o valor ) zero (0); à reação ( \pm ) o valor 0,5 ; à reação $(+)$ o valor 1 ; à reação $(++)$ o valor 2 ; e à reação $(+++)$ o valor

APara cada grupo, momentos representados por medianas seguidas de letras iguais não diferem significativamente $(p<0,05)$.

a Para cada momento, grupos representados por medianas seguidas de letras iguais não diferem significativamente $(p<0,05)$. das pelo teste de análise de variância de medidas repetidas (ANOVA) (Morrison 1990). Para comparar resultado de cada variável nos momentos dentro de cada grupo foi utilizado o Teste de Friedman. Para comparar resultados de cada variável entre os grupos, dentro de cada momento foi utilizado o Teste de Kruskal-Wallis. Todos os testes foram realizados ao nível de 5\% de variância $(P<0,05)$ (Curi 1997).

\section{RESULTADOS E DISCUSSÃO}

As análises pelo California Mastitis Test (CMT), contagem de células somáticas (CCS) e unidades formadoras de colônias (UFC/mL) das amostras de leite dos animais suplementados com vitamina $\mathrm{E}$ demonstraram valores significativamente $(P<0,05)$ menores quando comparados aos não suplementados (Quadros 1, 2 e 3). Segundo Poutrel \& Lerondelle (1983) e Contreras et al. (1996) o diagnóstico da mastite caprina pelo leite baseia-se principalmente no isolamento microbiológico, porém várias técnicas têm sido usadas para detectar a inflamação da glândula mamária, sendo as mais aceitas o California Mastitis Test (CMT), pela sua facilidade de utilização a campo e a contagem de células somáticas (CCS), em razão de sua sensibilidade e especificidade. Kalogridou-Vassiliadou et al. (1992), Deinhofer \& Pernthaner (1995) e Boscos et al. (1996) observaram que a CCS é útil na detecção da mastite caprina, desde que se considere o estágio da lactação e o número de partos. Apesar de às 48h após o tratamento (M7) não haver diferença

\footnotetext{
${ }^{10}$ BD Vacutainer ${ }^{\circledR}$, Becton, Dickinson and Company, Danby Building, Edmund Halley Road, Oxford Science Park, Oxford, Oxfordshire OX4 $4 \mathrm{DQ}$, Inglaterra.

${ }^{11}$ Proteína total ${ }^{\circledR}$, Gold Analisa Diagnóstica Ltda, Av. Nossa Senhora de Fátima 2363, Carlos Prates, Belo Horizonte, MG.

12 Celmgel $^{\circledR}$, Companhia Equipadora de Laboratórios Modernos (CELM), Alameda Amazonas 764, Alphaville, Barueri, SP.

${ }^{13}$ Densitômetro SB-210 ${ }^{\circledR}$, Companhia Equipadora de Laboratórios Modernos (CELM), Alameda Amazonas 764, Alphaville, Barueri, SP

${ }^{14}$ Goat IgG Antibody ${ }^{\circledR}$, Bethyl Laboratories, Inc, P.O. Box 850, Montgomery TX 77356, Texas, USA.

${ }^{15}$ Cromatógrafo Líquido de Alto Desempenho (HPLC) ${ }^{\circledR}$, Shimadzu do Brasil, Marquês de São Vicente 1771, Barra Funda, São Paulo, SP.
}

\section{Quadro 2. Medianas e análise estatística de sete repetições dos resultados} da contagem de células somáticas $\left(\times 10^{3}\right.$ células $/ \mathrm{mL}$ ) do leite de Cabras Saanen não suplementadas (G1) e suplementadas com $2.000 \mathrm{UI}$ de vitamina $E$ no dia do parto e 7 dias após o parto (G2 Vit E), nos momentos controle (M1), mastite (M2), 12 horas após a mastite (M3), 12 horas após a mastite (M4), 48 horas após a mastite (M5), 72 horas após a mastite (M6) e 48 horas após o tratamento com antibiótico intramamário (M7)

\begin{tabular}{|c|c|c|c|c|c|c|c|}
\hline \multirow[t]{2}{*}{ Grupos } & \multicolumn{7}{|c|}{ Momentos } \\
\hline & $\begin{array}{c}\mathrm{M} 1 \\
\text { Controle } \\
\left(\times 10^{3} \mathrm{c} / \mathrm{mL}\right)\end{array}$ & $\begin{array}{c}\mathrm{M} 2 \\
\text { Mastite } \\
\left(\times 10^{3} \mathrm{c} / \mathrm{mL}\right)\end{array}$ & $\begin{array}{c}\mathrm{M} 3 \\
12 \mathrm{~h} \mathrm{PM} \\
\left(\times 10^{3} \mathrm{c} / \mathrm{mL}\right)\end{array}$ & $\begin{array}{c}\mathrm{M} 4 \\
24 \mathrm{hPM} \\
\left(\times 10^{3} \mathrm{c} / \mathrm{mL}\right)\end{array}$ & $\begin{array}{c}\mathrm{M} 5 \\
48 \mathrm{hPM} \\
\left(\times 10^{3} \mathrm{c} / \mathrm{mL}\right)\end{array}$ & $\begin{array}{c}\mathrm{M} 6 \\
72 \mathrm{hPM} \\
\left(\times 10^{3} \mathrm{c} / \mathrm{mL}\right)\end{array}$ & $\begin{array}{c}\mathrm{M} 7 \\
48 \mathrm{PT} \\
\left(\times 10^{3} \mathrm{c} / \mathrm{mL}\right)\end{array}$ \\
\hline $\begin{array}{c}\text { G1 } \\
\text { G2 (Vit E) }\end{array}$ & $\begin{array}{l}74^{\mathrm{Aa}} \\
98^{\mathrm{Aa}}\end{array}$ & $\begin{array}{l}4.801^{\mathrm{Ba}} \\
1.058^{\mathrm{Aa}}\end{array}$ & $\begin{array}{c}10.000^{\mathrm{Bb}} \\
2.008^{\mathrm{Ac}}\end{array}$ & $\begin{array}{c}10.000^{\mathrm{Bc}} \\
3.384^{\mathrm{Ac}}\end{array}$ & $\begin{array}{c}6.849^{\mathrm{Bb}} \\
884^{\mathrm{Ac}}\end{array}$ & $\begin{array}{l}4.073^{\mathrm{Bb}} \\
1.504^{\mathrm{Ab}}\end{array}$ & $\begin{array}{c}1.691^{\mathrm{Bb}} \\
928^{\mathrm{Aa}}\end{array}$ \\
\hline
\end{tabular}

APara cada grupo, momentos representados por medianas seguidas de letras iguais não diferem significativamente $(p<0,05)$.

aPara cada momento, grupos representados por medianas seguidas de letras iguais não diferem significativamente $(p<0,05)$. 
Quadro 3. Medianas e análise estatística de sete repetições do exame microbiológico do leite (UFC/mL) do leite de cabras Saanen desafiadas com Staphyloccus aureus (G1) e suplementadas com $2.000 \mathrm{UI}$ de vitamina E no dia do parto e 7 dias após o parto (G2 Vit E) nos momentos controle (M1), mastite (M2), 12 horas após a mastite (M3), 12 horas após a mastite (M4), 48 horas após a mastite (M5), 72 horas após a mastite (M6) e 48 horas após o tratamento com antibiótico intramamário (M7)

\begin{tabular}{|c|c|c|c|c|c|c|c|}
\hline \multirow[t]{2}{*}{ Grupos } & \multicolumn{7}{|c|}{ Momentos } \\
\hline & $\begin{array}{c}\text { M1 } \\
\text { Controle } \\
\text { (UFC/mL) }\end{array}$ & $\begin{array}{c}\text { M2 } \\
\text { Mastite } \\
\text { (UFC/mL) }\end{array}$ & $\begin{array}{c}\mathrm{M} 3 \\
12 \mathrm{~h} P M \\
\text { (UFC/mL) }\end{array}$ & $\begin{array}{c}\mathrm{M} 4 \\
24 \mathrm{hPM} \\
\text { (UFC/mL) }\end{array}$ & $\begin{array}{c}\text { M5 } \\
\text { 48hPM } \\
\text { (UFC/mL) }\end{array}$ & $\begin{array}{c}\mathrm{M6} \\
72 \mathrm{hPM} \\
\text { (UFC/mL) }\end{array}$ & $\begin{array}{c}\mathrm{M7} \\
48 \mathrm{PT} \\
\text { (UFC/mL) }\end{array}$ \\
\hline $\mathrm{G}$ & $\mathrm{O}^{\mathrm{Aa}}$ & $500^{\mathrm{Bb}}$ & $200^{\mathrm{Bb}}$ & $210^{\mathrm{Bb}}$ & $20^{\mathrm{Bb}}$ & $40^{\mathrm{Ba}}$ & $\mathrm{O}^{\mathrm{Aa}}$ \\
\hline G2 (Vit E) & $0^{A a}$ & $100^{\mathrm{Ab}}$ & $290^{A b}$ & $50^{A b}$ & $10^{\mathrm{Ab}}$ & $10^{\mathrm{Aa}}$ & $0^{\mathrm{Aa}}$ \\
\hline
\end{tabular}

APara cada grupo, momentos representados por medianas seguidas de letras iguais não diferem significativamente $(p<0,05)$

aPara cada momento, grupos representados por medianas seguidas de letras iguais não diferem significativamente $(p<0,05)$.

significativa na concentração de bactérias (UFC) entre os grupos, a CCS e o CMT apresentaram diferenças significativas com os menores valores no grupo suplementado. Os valores mais baixos de CCS e CMT para a glândula mamária das cabras tratadas com vitamina $\mathrm{E}$ comprovam o efeito da suplementação, que diminui a severidade da mastite também observado em vacas por Smith et al. (1984), Politis et al. (1995) e Smith et al. (1997). Porém, Zanetti et al. (1998) e Ferreira et al. (2007) não encontraram diminuição da mastite subclínica diagnosticada por meio do teste CMT em vacas recebendo vitamina E. O grupo suplementado apresentou valores mais baixos de UFC sugerindo o efeito da vitamina E na proteção contra infecções intramamárias (Smith et al. 1997, Weiss et al. 1997). Outro benefício da utilização da CCS é que segundo Sears et al. (1990) a eliminação do $S$. aureus é cíclica gerando resultados falso-negativos, por isso sugere-se realizar um segundo exame microbiológico naqueles animais com alta CCS e com resultados microbiológicos negativos. Os resultados de menor presença de bactérias e menor CCS nos animais suplementados com vitamina $E$ neste experimento podem ser justificados pelo aumento na fagocitose dos neutrófilos (Ndiweni \& Finch 1996) e maior capacidade de eliminação de bactérias (Gyang et al. 1984). A concentração de vitamina E sérica (Quadro 4)

\section{Quadro 4. Valores das medianas das concentrações séricas de vitamina $E(\mathrm{~g} / \mathrm{mL})$ de cabras Saanen} primíparas, não suplementadas (G1) e suplementadas com 2.000 Ul de vitamina E no dia do parto e sete dias após o parto (G2 Vit E) nos momentos controle (M1), mastite (M2), 48 horas após a mastite (M3) e 48 horas após o tratamento com antibiótico intramamário (M4)

\begin{tabular}{ccccc}
\hline \multirow{2}{*}{ Grupos } & \multicolumn{4}{c}{ Momentos } \\
\cline { 2 - 5 } & $\begin{array}{c}\text { M1 } \\
\text { Controle } \\
(\mathrm{g} / \mathrm{mL})\end{array}$ & $\begin{array}{c}\text { Mastite } \\
(\mathrm{g} / \mathrm{mL})\end{array}$ & $\begin{array}{c}\text { M3 } \\
48 \mathrm{~h} \text { PM } \\
(\mathrm{g} / \mathrm{mL})\end{array}$ & $\begin{array}{c}\text { M4 } \\
48 \mathrm{~h} P T \\
(\mathrm{~g} / \mathrm{mL})\end{array}$ \\
\hline G1 & $0,65^{\mathrm{a}^{*}}$ & $0,56^{\mathrm{a}}$ & $0,65^{\mathrm{a}}$ & $1,26^{\mathrm{a}}$ \\
G2 (Vit E) & $0,87^{\mathrm{a}}$ & $1,09^{\mathrm{a}}$ & $1,34^{\mathrm{a}}$ & $1,50^{\mathrm{b}}$
\end{tabular}

*Medianas com letras não ligadas por mesma letra, minúsculas na vertical diferem pelo teste de Friedman à nível de $5 \%$ de significância. não diferiu significativamente $(P<0,05)$ nos grupos não suplementado (G1) e suplementado (G2 Vit E) exceto no momento M4, porém no grupo suplementado (G2 Vit E) a concentração foi sempre superior ao do grupo não suplementado (G1). O soro das cabras analisadas apresentou cinco frações protéicas: albumina e $\alpha 1, \beta 1, \beta 2$ e $\gamma$-globulinas (Fig.1) concordando com os achados de Castro et al. (1977), Santa Rosa et al. (2005) e Kaneko (2008), mas diferindo dos rela-

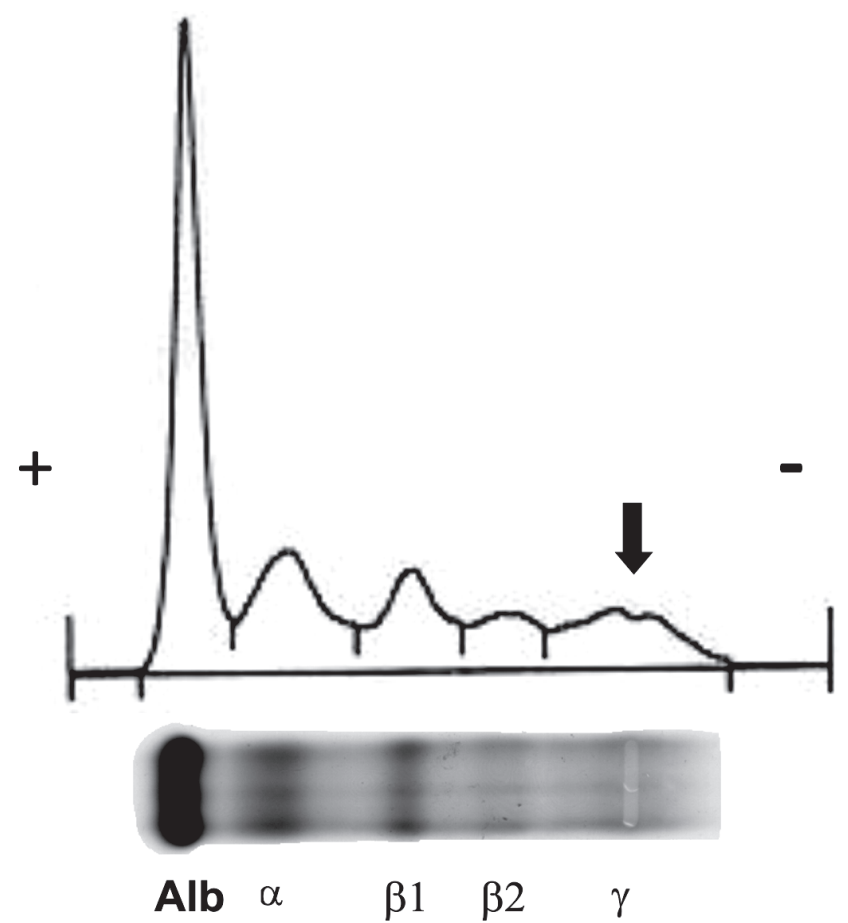

Fig.1. Representação gráfica da leitura em espectrofotômetro das proteínas séricas de cabras Saanen, demonstrando as cinco frações protéicas (albumina e $\alpha 1, \beta 1, \beta 2$ e $\alpha$-globulina) encontradas em animais não suplementados e suplementados com $2.000 \mathrm{UI}$ de vitamina E no dia do parto e sete dias após o parto. Os sinais, positivo e negativo demonstram o sentido da corrida eletroforética e a seta, o ponto de aplicação das amostras no gel. 
Quadro 5. Valores de média e desvios-padrão ( $x \pm d s)$ das concentrações de proteína total (PTS), albumina, $\alpha, \beta 1, \beta 2, \gamma$ globulinas e IgG do soro de cabras Saanen primíparas, não suplementadas (G1) e suplementadas com 2.000 UI de vitamina E no dia do parto e sete dias após o parto (G2 Vit E) e desafiadas com $S$. aureus nos momentos controle (M1), mastite (M2), 12 horas após a mastite (M3), 12 horas após a mastite (M4), 48 horas após a mastite (M5), 72 horas após a mastite (M6) e 48 horas após o tratamento com antibiótico intramamário (M7)

\begin{tabular}{|c|c|c|c|c|c|c|c|c|}
\hline \multicolumn{2}{|c|}{ Momentos } & \multirow{2}{*}{$\begin{array}{l}\text { PTS } \\
\text { (g/dL) }\end{array}$} & \multirow[t]{2}{*}{ Albumina (g/dL) } & \multicolumn{5}{|c|}{ Globulinas } \\
\hline & & & & $\alpha(\mathrm{g} / \mathrm{dL})$ & $\beta 1(\mathrm{~g} / \mathrm{dL})$ & $\beta 2(\mathrm{~g} / \mathrm{dL})$ & $\gamma(\mathrm{g} / \mathrm{dL})$ & $\lg G(\mathrm{mg} / \mathrm{dL})$ \\
\hline \multirow[t]{2}{*}{ M1 Controle } & G1 & $7,16 \pm 0,51 \mathrm{Aa}$ & $3,35 \pm 0,50 \mathrm{Aa}$ & $1,08 \pm 0,30 \mathrm{Aa}$ & $1,04 \pm 0,17 \mathrm{Aa}$ & $0,47 \pm 0,08 \mathrm{Aa}$ & $1,21 \pm 0,13 \mathrm{Aa}$ & $1348,9 \pm 257,8 \mathrm{Aa}$ \\
\hline & G2 (Vit E) & $6,14 \pm 0,47 \mathrm{Ba}$ & $2,83 \pm 0,20 \mathrm{Ba}$ & $0,91 \pm 0,04 \mathrm{Aa}$ & $0,82 \pm 0,09 \mathrm{Ba}$ & $0,35 \pm 0,06 \mathrm{Ba}$ & $4 \pm 0,28 A a$ & $1351,4 \pm 607,3 \mathrm{Aab}$ \\
\hline M2 Mastite & G2(Vit E) & $6,03 \pm 0,45 \mathrm{Ba}$ & $2,73 \pm 0,24 \mathrm{Aa}$ & $0,89 \pm 0,06 \mathrm{Aa}$ & $0,80 \pm 0,08 \mathrm{Ba}$ & $0,40 \pm 0,08 \mathrm{Ba}$ & $1,21 \pm 0,28 \mathrm{Aa}$ & $1101,7 \pm 645,5 \mathrm{Aa}$ \\
\hline \multirow[t]{2}{*}{ M3 12hPM } & G1 & $7,33 \pm 0,35 \mathrm{Aa}$ & $3,45 \pm 0,64 \mathrm{Aa}$ & $1,07 \pm 0,29 \mathrm{Aa}$ & $1,02 \pm 0,17 \mathrm{Aa}$ & $0,60 \pm 0,16 \mathrm{Aa}$ & $1,14 \pm 0,31 \mathrm{Aa}$ & $1650,9 \pm 529,7 \mathrm{Aa}$ \\
\hline & G2(Vit E) & $6,51 \pm 0,68 \mathrm{Ba}$ & $2,95 \pm 0,32 A a$ & $0,92 \pm 0,05 \mathrm{Aa}$ & $0,80 \pm 0,14 \mathrm{Ba}$ & $0,43 \pm 0,13 \mathrm{Ba}$ & $1,41 \pm 0,28 \mathrm{Aa}$ & $1690,0 \pm 503,8 \mathrm{Ab}$ \\
\hline \multirow[t]{2}{*}{ M5 48hPM } & G1 & $6,80 \pm 0,55 \mathrm{Aa}$ & $3,27 \pm 0,31 \mathrm{Aa}$ & $1,00 \pm 0,26 \mathrm{Aa}$ & $0,86 \pm 0,15 A a$ & $0,66 \pm 0,18 \mathrm{Aa}$ & $1,00 \pm 0,19 \mathrm{Aa}$ & $1692,9 \pm 431,7 \mathrm{Aa}$ \\
\hline & G2(Vit E) & $6,00 \pm 0,55 \mathrm{Ba}$ & $2,74 \pm 0,27 \mathrm{Ba}$ & $0,90 \pm 0,06 \mathrm{Aa}$ & $0,75 \pm 0,09 A a$ & $0,37 \pm 0,06 \mathrm{Ba}$ & $1,24 \pm 0,33 \mathrm{Aa}$ & $1596,7 \pm 605,4 \mathrm{Ab}$ \\
\hline \multirow[t]{2}{*}{ M6 72hPM } & $\mathrm{G} 1$ & $6,96 \pm 0,38 \mathrm{Aa}$ & $3,14 \pm 0,43 A a$ & $1,06 \pm 0,26 \mathrm{Aa}$ & $0,94 \pm 0,19 A a$ & $0,64 \pm 0,26 \mathrm{Aa}$ & $1,11 \pm 0,14 \mathrm{Aa}$ & $1387,6 \pm 341,5 \mathrm{Aa}$ \\
\hline & G2(Vit E) & $6,27 \pm 0,64 \mathrm{Ba}$ & $2,74 \pm 0,37 \mathrm{Aa}$ & $0,94 \pm 0,09 \mathrm{Aa}$ & $0,81 \pm 0,15 \mathrm{Aa}$ & $0,37 \pm 0,04 \mathrm{Ba}$ & $1,40 \pm 0,32 \mathrm{Ba}$ & $1533,6 \pm 651,7 \mathrm{Aab}$ \\
\hline \multirow[t]{2}{*}{ M7 48hPT } & G1 & $7,26 \pm 0,56 \mathrm{Aa}$ & $3,17 \pm 0,65 \mathrm{Aa}$ & $1,10 \pm 0,23 \mathrm{Aa}$ & $1,04 \pm 0,22 A a$ & $0,66 \pm 0,38 \mathrm{Aa}$ & $1,24 \pm 0,16 \mathrm{Aa}$ & $1685,0 \pm 463,1 \mathrm{Aa}$ \\
\hline & G2(Vit E) & $6,33 \pm 0,80 \mathrm{Ba}$ & $2,84 \pm 0,36 \mathrm{Aa}$ & $0,96 \pm 0,09 \mathrm{Aa}$ & $0,79 \pm 0,12 \mathrm{Ba}$ & $0,39 \pm 0,11 \mathrm{Aa}$ & $1,35 \pm 0,37 \mathrm{Aa}$ & $1622,1 \pm 529,4 \mathrm{Ab}$ \\
\hline
\end{tabular}

APara cada grupo, momentos representados por médias seguidas de letras iguais não diferem significativamente $(p<0,05)$.

apara cada momento, grupos representados por médias seguidas de letras iguais não diferem significativamente $(p<0,05)$.

tados por Ferri et al. (1970) e Birgel \& Ferri (1971), que observaram quatro frações eletroforéticas (albumina e globulinas $\alpha, \beta$ e $\gamma$ ) e Chen et al. (1999) (albumina e $\alpha 1$, $\alpha 2$ e $\gamma$-globulinas), de Machado (1979) com sete frações eletroforéticas, (albumina e globulinas $\alpha 1, \alpha 2, \alpha 3, \beta 1, \beta 2$ e $\gamma$ ) e de Ciarlini et al. (1994) com cinco frações eletroforéticas (albumina e globulinas $\alpha_{1}, \alpha_{2}, \beta$ e $\gamma$ ). Segundo Jain (1986) os resultados obtidos no fracionamento eletroforético em diferentes técnicas podem diferir significativamente, dificultando a sua comparação. A concentração de proteína total sérica para os grupos, não suplementado e suplementado, apresentou diferenças significativas $(P<0,05)$ em todos os momentos, porém o comportamento dessas proteínas durante o desenvolvimento e processo de resolução da mastite foi muito semelhante (Quadro 5).

Para a variável albumina houve diferença significativa $(P<0,05)$ apenas nos momentos M1 e M5, e acompanham o raciocínio com relação às proteínas totais séricas, pois a albumina constituiu-se na maior fração presente no soro, com cerca de $40 \%$. Porém, houve tendência em ambos os grupos, não suplementado e suplementado, à diminuição da albumina no momento do desenvolvimento da mastite (M2), que pode ser explicado pela mobilização de fluídos e proteínas para a glândula mamária, devido ao processo inflamatório induzido pela inoculação de Staphylococcus aureus. A albumina é considerada uma proteína de fase aguda negativa, diminuindo durante o processo inflamatório (Kaneko 2008).

Segundo Kaneko (2008) a fração $\alpha$-globulina é constituída de $\alpha 2$-macroglobulina, haptoglobina, ceruloplasmina, soro amiloide A, antitripisina e antiquimiotripsina, importantes proteínas de fase aguda que se elevam em processos inflamatórios. Porém, não foi observada elevação significativa $(P<0,05)$ desta fração durante a indução da mastite.

Os valores médios da fração $\beta 1$-globulina não sofre- ram variações significativas $(P<0,05)$, permanecendo dentro da média do grupo controle, concordando com os achados de Smith \& Sherman (1994).

Os resultados não demonstraram diferenças significativas $(P<0,05)$ da fração $\beta 2$-globulina entre os momentos para ambos os grupos, não suplementado e suplementado, porém quando se comparou entre grupos, houve diferença entre alguns momentos (Quadro 5). No grupo não suplementado, houve tendência ao aumento gradativo da fração $\beta 2$-globulina até o momento $M 5$, sendo que no grupo suplementado o aumento foi gradativo somente até o momento M3. Segundo Kaneko (2008) a fração $\beta 2-$ globulina é constituída de algumas proteínas de fase aguda, dentre elas a proteína $C$ reativa e as frações C3 e C4 do complemento. Estas proteínas de fase aguda funcionam como indicadores de doenças nos estágios iniciais da inflamação. Essa resposta inflamatória para o tecido lesado é um mecanismo fundamental, no qual o organismo monta uma defesa contra a lesão e inicia uma série de eventos químicos para desencadear o processo de cura. Estes eventos químicos são mediados pela liberação de citocinas pelos leucócitos que migram para o local da lesão. A interleucina 1 (IL-1), interleucina 6 (IL-6) e o fator de necrose tumoral alfa (TNF-a) são importantes citocinas liberadas na circulação que alcançam o fígado e induzem a síntese e liberação das proteínas de fase aguda. Ciarlini et al. (1994) estudando caprinos infectados por Corynebacterium pseudotuberculosis observaram aumento da fração $\beta$-globulina.

Em relação às concentrações séricas de vitamina $E$ observou-se diferença significativa $(P<0,05)$ entre grupos no momento $\mathrm{M} 4$, com maiores concentrações de vitamina E para os animais do grupo suplementado (Quadro 4). A vitamina $\mathrm{E}$ é o mais potente antioxidante biológico, importante na defesa de células e tecidos (Paschoal et al. 
2003) e a suplementação em doses elevadas pode aumentar a resposta humoral e celular (Meydany \& Hayek 1997) prevenir enfermidades como mastite (Weiss et al. 1997, Valle 2000) e reduzir distúrbios reprodutivos (Weiss et al. 1990). Diversos autores relataram redução na ocorrência de mastites em vacas suplementadas com tocoferol (Batra et al. 1992, Jukola et al. 1996, Zanetti et al. 1998, Valle 2000, Paschoal et al. 2003), entretanto, em outros estudos, não foi observado efeito benéfico sobre a imunidade da glândula mamária (Ndiweni et al. 1991, Costa et al. 1997, Erskine et al. 1997). A vitamina E é um excelente antioxidante capaz de capturar radicais livres impedindo a lipoperoxidação da membrana da célula durante o processo inflamatório e consequentemente mantendo a sua integridade (Reddy \& Frey 1990, Mcdowell et al. 1996, Chan 1996). A diminuição da extensão da lesão na glândula mamária nos animais suplementados pode explicar a menor produção das proteínas de fase aguda, pela diminuição na produção das interleucinas, liberadas durante a lesão tecidual (Reddy \& Frey 1990, McDowell et al. 1996). A suplementação com vitamina $E$ diminui a geração de superóxidos produzidos pelos polimorfonucleares e diminui a liberação de espécies reativas de oxigênio (EROS), peroxidação lipídica e IL-1 pelos monócitos. A diminuição da liberação de EROS e da oxidação lipídica ocorre pela inibição da atividade da proteína $\mathrm{C}$ quinase (proteína de fase aguda localizada na fração $\beta$-globulina) pelo $\alpha$-tocoferol (Azzi \& Stocker 2000, Kaneko 2008). A função imunoregulatória da vitamina E pode também estar relacionada ao seu papel na alteração do metabolismo do ácido araquidônico e conseqüentemente na biosíntese de prostaglandinas, tromboxane e leucotrienos diminuindo o efeito inflamatório (Reddy \& Frey 1990, McDowell et al. 1996).

Os resultados observados com relação à fração $\gamma$-globulina, demostraram não haver diferença significativa $(P<0,05)$ entre momentos para ambos os grupos, não suplementados e suplementados. Porém, comparandose entre grupos houve diferença significativa $(P<0,05)$ para o momento M6. O grupo não suplementado apresentou tendência à diminuição das imunoglobulinas iniciando-se no momento M2 até o momento M5, elevando-se até o momento M7. Esses dados podem estar relacionados com a produção e a utilização de imunoglobulinas. Sabe-se que as imunoglobulinas inespecíficas (IgM) são produzidas inicialmente em relação às específicas (IgG). O grupo suplementado com vitamina $E$ apresentou maiores valores de imunoglobulinas praticamente em todos os momentos, o que torna evidente sua ação na produção destas proteínas. Segundo Reddy et al. (1986) a suplementação com vitamina $\mathrm{E}$ em bezerros aumentou a concentração de IgM, sugerindo sua capacidade para aumentar a resposta imune primária. Os valores elevaram-se rapidamente após o momento (M2) da instalação da mastite, o que evidencia a maior produção celular de imunoglobulinas, provavelmente inespecífica (IgM), decrescendo gradativamente até o momento M5 e aumentando pos- teriormente, provavelmente devido a produção de imunoglobulinas específicas (IgG).

Não foram observados neste estudo diferenças significativas $(P<0,05)$ entre momentos do grupo não suplementado e entre grupos para a variável IgG. Porém, houve diferença entre alguns momentos (Quadro 5) quando comparados os grupos suplementado com vitamina E. Esses dados demonstram que não houve estímulo efetivo na produção de IgG pela vitamina $E$, ressaltando que a elevação encontrada na fração $\gamma$-globulina determinada pelo perfil eletroforético, provavelmente deva-se ao aumento na produção de outras imunoglobulinas. Segundo Cipriano et al. (1982), Reddy et al. (1986), Mudron et al. (1992), Hidiroglou et al. (1995) e Costa (2000) houve aumento não significativo na concentração de IgG para animais suplementados com vitamina $\mathrm{E}$.

\section{CONCLUSÃO}

A suplementação com $2.000 \mathrm{UI}$ de vitamina E no dia do parto e 7 dias após o parto em cabras foi efetiva para aumentar a produção de imunogloblinas e diminuir a produção de proteínas de fase aguda, evidenciando seu efeito protetor na glândula mamária durante o processo de mastite induzida experimentalmente por Staphylococcus aureus. Porém, mais estudos devem ser realizados para verificar os mecanismos de proteção da vitamina E na glândula mamária em animais de produção.

Agradecimentos.- À Fundação de Amparo a Pesquisa do Estado de São Paulo (FAPESP) pelo apoio financeiro e ao Laboratório de Nutrição da Faculdade de Medicina da Unesp, Campus de Botucatu.

\section{REFERÊNCIAS}

Arnaud J. 1991. Simultaneous determination for retinol, a-tocopherol and $b$-carotene in serum by isocratic high-performance liquid chromatography. J. Chromother. 572:103-116.

Azzi A. \& Stocker A. 2000. Vitamin E: Non-antioxidant roles. Progress in Lipid Res. 39(3):231-255.

Batra T.R., Hidiroglou M. \& Smith M.W. 1992. Effect of vitamin E on incidence of mastitis in dairy cattle. Can. J. Anim. Sci. 72(2):287-297.

Birgel E.H. \& Ferri S. 1971. Etudes par electrophorese sur papier des proteins serum normal des chevres anglo-nubienes. Rec. Med. Vet. 147:43-48.

Boscos C., Stefanakis A., Alexopoulos C. \& Samartzi F. 1996. Prevalence of subclinical mastitis and influence of breed, parity, stage of lactation and mammary bacteriological status on Coulter Counter Counts and California Mastitis Test in the milk of Saanen and autochthonous Greek goats. Small Ruminant Res. 21(2):139-147.

Broadhurst J. \& Paley C. 1939. A single-dip stain for the direct examination of milk. J. Am. Vet. Med. Assoc. 94:525-526.

Carter G.R. \& Cole Junior J.R. 1990. Diagnostic procedures in veterinary bacteriology and mycology. Academic Press, San Diego, p.201-209.

Castro A., Dhindsa D.S., Hoversland A.S. \& Metcalf J. 1977. Serum proteins and protein electrophoretic pattern in normal Pygmi Goats. Am. J. Vet. Res. 38(5):665-67.

Chan W. 1996. Cellular interation of vitamin E cytokines and growth factores. Nutrition Res. 16(3):427-434.

Chen J.C., Chang C.J., Peh H.C. \& Chen S.Y. 1999. Serum protein levels and neonatal growth rate of Nubian goat kids in Taiwan area. Small Ruminant Res. 32(2):153-160. 
Ciarlini P.C., Botelho G.G., Scherer P.O. \& Langenegger C.H. 1994. Proteinograma sérico de caprinos naturalmente infectados pelo Corynebacterium pseudotuberculosis. Revta Univ. Rural, Sér. Ciênc. Vida 16(1/2):91-95.

Cipriano J.E., Morril J.L. \& Anderson N.V. 1982. Effect of vitamin E on immune response of calves. J. Dairy Sci. 65(2):357-365.

Contreras A., Sierra D., Corrales J.C., Sanches A. \& Marco J. 1996. Physiological threshold of somatic cell count and California Mastitis Test for diagnosis of caprine subclinical mastitis. Small Ruminant Res. 21:259-264.

Costa E.O., Lucci C.S., Abe S.Y., White C.R., Ribeiro A.R., Watanabe E.T., Gabaldi S.A. \& Sa Filho R. 1997. Influência da suplementação de selênio na incidência de mastite. Ver. Bras. Med. Vet. 19(4):169172.

Costa J.N. 2000. Leucograma, metabolismo oxidativo dos neutrófilos, proteinogama e imunoglobulinas de bovinos da raça holandesa (Bos taurus): influência do desenvolvimento etário e da suplementação com acetato de dl-a-tocoferol. Tese de Doutorado em Veterinária, Faculdade de Medicina Veterinária e Zootecnia, Universidade Estadual Paulista, Botucatu. 209p.

Curi P.R. 1997. Metodologia e análise da pesquisa em ciências biológicas. Tipmic, Botucatu. p.220-224.

Deinhofer M. \& Pernthaner A. 1995. Staphylococcus spp. as mastitisrelated pathogens in goat milk. Vet. Microbiol. 43(2-3):161-166.

Erskine R.J., Bartlett P.C., Herdt T. \& Gaston P. 1997. Effects of parenteral administration of vitamin $\mathrm{E}$ on health of periparturient dairy cows. J. Am. Vet. Med. Assoc. 211(4):466-469.

Ferreira A.M.C.S., Costa J.N., Peixoto A.P.C., Brito O.S., Cassetari M.L., Neto O.A.C. 2007. Suplementação com vitamina E (acetato de DLalfa-tocoferol) e a ocorrência de mastite em vacas da raça Jersey. Rev. Brás. Saúde Prod. An. 8(2):71-82.

Ferri S., Birgel E.H. \& Silva R.A. 1970. Electrophoretic study of seric proteins in normal Toggenburg female goats with aging. Arch. Vet. Ital. 21(2):119-125.

Gyang E.O., Stevens J.B., Olson W.G., Tsitsamis S.D. \& Usenik E.A. 1984. Effects of selenium-vitamin $E$ injection on bovine polymorfonucleated leukocytes phagocytosis and killing of Staphylococcus aureus. Am. J. Vet. Res., 45(1):175-177.

Hidiroglou M., Batra T.R., Ivan M. \& Markham F. 1995. Effects of supplemental vitamin $E$ and $C$ on the immune responses of calves. J. Dairy Sci. 78(7):1578-83.

Jain N.C. 1986. Schalm's Veterinary Hematology. $4^{\text {th }}$ ed. Lea and Febiger, Philadelphia, p.956.

Jukola E., Hakkarainer J., Saloniemi H., Sankari S. 1996. Blood selenium, vitamin $\mathrm{E}$, vitamin $A$ and $\beta$-carotene concentrations and udder health, fertility treatments e fertility. J. Dairy Sci.79:838-845.

Kalogridou-Vassiliadou D., Manolkidis K. \& Tsigoida A. 1992. Somatic cell counts in relation to infection status of the goat udder. J. Dairy Res. 59(1):21-28.

Kaneko J.J. 2008. Clinical Biochemistry of Domestic Animals. $5^{\text {th }}$ ed. Academic Press, San Diego. 932p.

Lima Junior A.D. 1991. Fatores condicionantes da mastite subclínica caprina e os efeitos da doença sobre as características físico-químicas, celulares e microbiológicas do leite. Dissertação de Mestrado, UFRRJ, Rio de Janeiro. 117p.

Machado M.A. 1979. Proteína total, fracionamento eletroforético e fibrinogênio do sangue de caprinos confinados e em pastoreio semi-extensivo. Dissertação de Mestrado em Medicina Veterinária, Escola de Veterinária, Universidade Federal de Minas Gerais, Belo Horizonte. $35 p$.

McDowell L.R., Williams S.N., Hidiroglou N., Njeru C.A., Hill G.M., Ochoa L. \& Wilkinson N.S. 1996. Vitamin E supplementation for the ruminant. Anim. Feed Sci. Technol. 60(3/4):273-296.
Meydany S.N. \& Hayek M.G. 1997. Vitamin E and the aging immune response. Proc. $15^{\text {th }}$ Animal Veterinary Medical Forum, Florida. Florida American College of Veterinary, p.114-115.

Morrison D.F. 1990. Multivariate Statistical Methods. $3^{\text {rd }}$ ed. McGraw Hill, São Paulo. p.236-254.

Mudron P., Kovác G., Hojerová A., Bartro P., Bíres J., Michna A. \& Baldovic R. 1992. The effect of administration of vitamin $E$ on levels of serum immunoglobulins and levels of phagocytic activity. Vet. Med. Praha. 37(11):587-594.

Ndiweni N. \& Finch J.M. 1996. Effects of in vitro supplementation with a -tocopherol and selenium on bovine neutrophil functions: Implications for resistance to mastitis. Vet. Immunol. Immunopathol. 51:67-78.

Ndiweni N., Field T.R., Williams M.R., Booth J.M. \& Finch J.M. 1991. Studies on the incidence of clinical mastitis and blood levels of vitamin $\mathrm{E}$ and selenium in dairy herds in England. Vet. Rec. 129(5):86-88.

Paschoal J.J., Zanetti M.A. \& Cunha J.A. 2003. Efeito da suplementação de selênio e vitamina $E$ sobre a incidência de mastite clínica em vacas da raça holandesa. Arq. Bras. Med. Vet. Zootec. 55(3):249255.

Politis I., Hidiroglou M., Batra T.R., Gilmore J.A., Gorewit R.C. \& Scherf H. 1995. Effects of vitamin $E$ on immune function of dairy cows. Am. J. Vet. Res. 56(2):179-184.

Poutrel B. \& Lerondelle C. 1983. Cell content of goat milk: California Mastitis Test, Coulter Counter, and Fossomatic for predicting half infection. J. Dairy Sci. 66(12):2575-2579.

Preescot S.C. \& Breed R.S. 1910. The determination of the number of body cells in milk by direct method. J. Infect. Dis. 7(5):632-646.

Reddy P.G. \& Frey A. 1990. Nutritional modulation of immunity in domestic food animals. In: Blecha F. \& Charley B. (Eds), Immunomodulation in Domestic Food Animals. Adv. Vet. Sci. Comp. Med. 35:255-281.

Reddy P.G., Morrill J.L., Minocha H.C., Morrill M.B., Dayton A.D. \& Frey R.A. 1986. Effect of supplemental vitamin $E$ on the immune system of calves. J. Dairy Sci. 69(1):164-171.

Santa Rosa K.T., Rocha e Silva R.C., Silva J.B.A. \& Soto-Blanco B. 2005. Valores de referência para o perfil eletroforético de proteína sérica em cabras. Arch. Vet. Sci. 10(3):46-48.

Santos E.C. \& Virela M.A.P. 1983. Pesquisa de células somáticas no leite cru como critério de avaliação de qualidade. Arq. Bras. Med. Vet. Zootec. 35:907-919.

Schalm O.W. \& Noorlander D.D. 1957. Experiments and observations leading to development of the California Mastitis Test. J. Am. Vet. Med. Assoc. 130:199-204.

Sears P.M., Smith B.S., English P.B., Herer P.S. \& Gonzales R.N. 1990. Shedding pattern of Staphylococcus aureus from bovine intramammary infections. J. Dairy Sci. 73(10):2785-2789.

Silva J.A.B.A. 1991. Magnitude, resistência e recuperação das características do leite na mastite induzida por Streptococcus agalactiae. Dissertação de Mestrado, Universidade Federal Rural do Rio de Janeiro, Seropédica, RJ. 113p.

Smith K.L., Conrad H.R., Amiet B.A., Schoenberger P.S. \& Todhunter D.A. 1985. Effect of vitamin $E$ and selenium dietary supplementation on mastits on first lactation dairy cows. J. Dairy Sci. 68(Suppl.1):190. (Abstract)

Smith K.L., Harrison J.H., Hancock D.D., Todhunter D.A. \& Conrad H.R. 1984. Effect of vitamin $E$ and selenium supplementation on incidence of clinical mastitis and duration of clinical symptoms. J. Dairy Sci. 67(6):1293-1300.

Smith K.L., Hogan J.S. \& Weiss W.P. 1997. Dietary vitamin E and selenium affect mastitis and milk quality. J. Anim. Sci. 75(6):16591665.

Smith M.C. \& Sherman D.M. 1994. Goat Medicine. Lea and Febiger, Philadelphia, p.200. 
Valle C.R. 2000. Influência da suplementação de vitamina E nos períodos pré e pós-parto na ocorrência de mastite clínica. Dissertação de Mestrado em Zootecnia, Faculdade de Zootecnia e Engenharia de Alimentos, USP, São Paulo. 76p.

Weiss W.P., Hogan J.S., Todhunter D.A. \& Smith K.L. 1997. Effect of vitamin $\mathrm{E}$ supplementation in diets with a low concentration of selenium on mammary gland health of dairy cows. J. Dairy Sci. 80(8):1728-1737.

Weiss W.P., Hogan J.S. \& Smith K.L. 1994. Use of $\alpha$-tocopherol concentrations in blood components to asses vitamin E status of dairy cows. Agri-Pract. 15(7):5-8.

Weiss W.P., Todhunter D.A., Hogan J.S., Smith K. L. 1990. Effect of duration of supplementation of selenium and vitamin $E$ on periparturient dairy cows. J. dairy Sci. 73(11):3187-3194.

Zanetti M.A., Neunhaus L.E.D., Schalch E. \& Martins J.H. 1998. Efeito da suplementação de Selênio e Vitamina E em bovinos leiteiros. Revta Bras. Zootec. 27:405-408. 